\title{
KẾT QUẢ SỚM PHẪU THUẬT THAY VAN TIM TẠI BỆNH VIỆN ĐA KHOA TỈNH QUẢNG NINH
}

\author{
Phạm Việt Hùng ${ }^{1}$, Trịnh Văn Mạnh ${ }^{1}$, Nguyễn Huy Tiến ${ }^{1}$, Nguyễn Thị Thoa ${ }^{1}$, Ngô Văn Tuấn ${ }^{1}$, \\ Nguyễn Hũu U'ớc ${ }^{2,3}$, Phùng Duy Hồng Sơn ${ }^{2}$, Vũ Ngoc Tư ${ }^{3 *}$
}

\section{TÓM TẮT:}

Tổng quan: Bệnh van tim là bệnh tim mạch phổ biến với số lượng lớn bệnh nhân cần phẫu thuật. Tuy nhiên triển khai phẫu thuật thay van tim tại bệnh viện tuyến tỉnh là một thách thức lớn. Nghiên cứu được thực hiện để đánh giá hiệu quả và lợi ích khi triển khai phẫu thuật thay van tim tại Bệnh viện đa khoa tỉnh Quảng Ninh.

Đối tự̛ng và phương pháp nghiên cứu: nghiên cứu mô tả cắt ngang cho 59 bệnh nhân được phẫu thuật thay van tim tại Bệnh viện đa khoa tỉnh Quảng Ninh, từ tháng 5/2016 đến tháng 12/2020.

Kết quả: Tuổi trung bình bệnh nhân là $53 \pm$ 11,7 (từ 22 đến 71 tuổi). Tất cả có biểu hiện có triệu chứng suy tim trước mổ NYHA II, III. Thay van 2 lá: 42 bệnh nhân, van động mạch chủ: 7 bệnh nhân, van hai lá và van động mạch chủ đồng thời: 10 bệnh nhân. Thời gian trung bình của phẫu thuật: $230 \pm 41,2$ phút, tuần hoàn ngoài cơ thể: $136 \pm 39,8$ phút; cặp động mạch chủ: $106 \pm 36,7$ phút. Thời gian thở máy dưới $6 \mathrm{~h}$ chiếm $89,8 \%$. Có $98,3 \%$ bệnh nhân ra viện với kết quả tốt.

Kết luận: Bệnh viện đa khoa tỉnh Quảng Ninh đã triển khai phẫu thuật tim hở nói chung và thay van tim nói riêng an toàn và hiệu quả cao.

Tù khóa: bệnh van tim, thay van tim, Bệnh viện đa khoa tỉnh Quảng Ninh

\section{ABSTRACT}

EARLY RESULTS OF ARTIFICIAL HEART VALVE REPLACEMENT AT QUANG NINH PROVINCIAL GENERAL HOSPITAL

Background: Valvular heart disease is a common cardiovascular disease with a large number of patients requiring surgery. However, implementing heart valve replacement surgery at provincial hospitals is a big challenge. The study was conducted to evaluate the effectiveness and benefits of heart valve replacement surgery at Quang Ninh General Hospital.

Methods: a cross-sectional descriptive study for 59 patients underwent heart valve replacement surgery at Quang Ninh General Hospital, from May 2016 to December 2020.

Results: The mean age of patients was $53 \pm$ 11.7 years (from 22 to 71 years). All had symptoms of heart failure before surgery NYHA II, III. Mitral valve replacement: 42 patients, aortic valve replacement: 7 patients, both mitral and aortic valve replacement: 10 patients. Average time of surgery: $230 \pm 41.2$ minutes, CPB mean time: $136 \pm 39.8$ minutes; aortic cross - clamp mean time: $106 \pm$ 36.7 minutes. The postoperative lung ventilation time $<6$ hours accounted for $89.8 \%$. There were $98.3 \%$ patients discharged with good results.

\section{Conclusion: Quang Ninh Provincial}

\footnotetext{
${ }^{I}$ Bệnh viện đa khoa tỉnh Quảng Ninh

${ }^{2}$ Bệnh viện Việt Đức

${ }^{3}$ Truoòng Đại học Y Hà Nội

*Tác giả liên hệ:Vũ Ngoc Tú; Email: vungoctu@hmu.edu.vn:

Ngày nhận bài:01/08/2021 ～Ngày Cho Phép Đăng: 30/09/2021
} 
General Hospital has implemented safe and highly effective open-heart surgery in general and heart valve replacement in particular.

Keywords: valvular heart disease, heart valve replacement, Quang Ninh Provincial General Hospital

\section{TỔNG QUAN}

Bệnh van tim vẫn là một bệnh phổ biến tại Việt Nam, nguyên nhân chủ yếu do thấp. Phẫu thuật thay van tim là một trong loại phẫu thuật tim hở phổ biến nhất tại các trung tâm phẫu thuật tim mạch lớn, nhưng ở các bệnh viện tuyến tỉnh tại Việt Nam như Bệnh viện đa khoa
Tỉnh Quảng Ninh là một cố gắng rất lớn. Từ ca mổ tim hở đầu tiên vào năm 2016, đến nay gần 100 ca mổ tim hở đã được thực hiện thành công tại đây, trong đó có một số lượng lớn bệnh nhân được thay van tim. Để rút ra những kinh nghiệm trong thời gian triển khai mổ tim hở tại Quảng Ninh và đánh giá kết quả phẫu thuật, chúng tôi tiến hành nghiên cứu này nhằm: $m o ̂$ tả một số đặc điểm bệnh lý của nhóm bệnh nhân và đánh giá kết quả sớm của phẫu thuật thay van tim nhân tạo tại Bệnh viện đa khoa tinh Quảng Ninh.

\section{2. ĐỐI TƯợNG VÀ PHƯƠNG PHÁP NGHIÊN CÚU}

Nghiên cứu mô tả cắt ngang tất cả bệnh nhân được phẫu thuật thay van tim tại Bệnh viện đa khoa tỉnh Quảng Ninh từ tháng 5/2016 - tháng 12/2020.

\section{KẾT QUẢ}

Trong thời gian từ tháng 5/2016 đến tháng 12/2020 tại bệnh viện đa khoa tỉnh Quảng Ninh có 59 bệnh nhân đủ tiêu chuẩn nghiên cứu với các đặc điểm như sau.

\section{1. Đặc điểm trước phẫu thuật}

Bảng 3.1: Đặc điểm lâm sàng trước phẫu thuật $(N=59)$

\begin{tabular}{|l|l|c|l|}
\hline \multirow{3}{*}{ Tuổi } & \multicolumn{1}{|c|}{ Trung bình } & \multicolumn{1}{|c|}{$\leq \mathbf{6 0}$} & \multicolumn{1}{c|}{$>\mathbf{6 0}$} \\
\cline { 2 - 4 } & \multicolumn{1}{|c|}{$53 \pm 11,7$} & $72,9 \%$ & \multicolumn{1}{c|}{$\mathbf{~ N a m}$} \\
\hline \multirow{3}{*}{ Giới } & \multicolumn{1}{|c|}{$61,0 \%$} & $39,0 \%$ \\
\hline \multirow{5}{*}{ Tiền sử } & Đặc điểm & \multicolumn{1}{c|}{ Số bệnh nhân (n, \%) } \\
\cline { 2 - 4 } & Thấp tim & $52(88)$ \\
\cline { 2 - 3 } & Nong van hai lá & $5(8,5)$ \\
\cline { 2 - 3 } & Tách van tim kín & $2(3,4)$ \\
\cline { 2 - 3 } & Mổ thay van tim & $1(1,7)$ \\
\cline { 2 - 3 } & Tai biến mạch não & $10(16,9)$ \\
\cline { 2 - 3 } & Bệnh mạch ngoại vi & $2(3,4)$ \\
\cline { 2 - 3 } & Đái tháo đường & $15(25,4)$ \\
\hline
\end{tabular}


Bảng 3.2: Kết quả chẩn đoán cận lâm sàng trước phẫu thuật $(N=59)$

\begin{tabular}{|c|c|c|}
\hline \multicolumn{2}{|l|}{ Điện tim } & Số bệnh nhân (n, \%) \\
\hline \multicolumn{2}{|l|}{ Rung nhĩ } & $28(47,0 \%)$ \\
\hline \multicolumn{3}{|l|}{ Siêu âm tim } \\
\hline \multirow{5}{*}{ Van hai lá } & Hở vừa - nhiều & $12(21,4 \%)$ \\
\hline & Hẹp vừa - nhiều & $32(57,1 \%)$ \\
\hline & Lá van dày - vôi & $32(57,1 \%)$ \\
\hline & Sa lá van & $4(6,8 \%)$ \\
\hline & Khác & $4(6,8 \%)$ \\
\hline \multirow{5}{*}{ Van động mạch chủ } & Hẹp vừa - nhiều & $7(11,8 \%)$ \\
\hline & Hở vừa - nhiều & $6(10,2 \%)$ \\
\hline & Lá van dày, vôi & $7(11,8 \%)$ \\
\hline & Lá van dạng hai lá & $2(3,4 \%)$ \\
\hline & Khác & $2(3,4 \%)$ \\
\hline \multicolumn{2}{|c|}{ Hở chức năng van ba lá vừa - nhiều } & $22(37,3 \%)$ \\
\hline \multicolumn{2}{|c|}{ Huyết khối nhĩ trái } & $15(25,4 \%)$ \\
\hline \multirow{2}{*}{\multicolumn{2}{|c|}{$\begin{array}{l}\text { Tổn thương phối hợp khác (thông liên nhĩ, thông liên thất, giãn } \\
\text { động mạch chủ lên ...) }\end{array}$}} & $5(8,5 \%)$ \\
\hline & & Trung bình \\
\hline \multicolumn{2}{|c|}{ Áp lực ĐMP tâm thu - PAPs (mmHg) } & $47,1 \pm 12,28(25-82)$ \\
\hline \multicolumn{2}{|c|}{ Phân suất tống máu EF (\%) } & $62,9 \pm 6,69(48-76)$ \\
\hline \multicolumn{2}{|c|}{ Đường kính nhĩ trái (mm) } & $48,2 \pm 10,26(29-81)$ \\
\hline \multicolumn{2}{|c|}{ Đường kính thất trái tâm trương - $\mathrm{Dd}(\mathrm{mm})$} & $51,5 \pm 7,63(36-74)$ \\
\hline \multicolumn{2}{|c|}{ Đường kính thất trái tâm thu - Ds (mm) } & $34,3 \pm 6,42(24-50)$ \\
\hline \multicolumn{2}{|c|}{ Đường kính thất phải (mm) } & $21,1 \pm 2,97(15-32)$ \\
\hline
\end{tabular}

\section{2. Đặc điểm phẫu thuật}

Bảng 3.3: Thời gian phẫu thuật $(N=59)$

\begin{tabular}{|l|c|c|c|c|}
\hline Thời gian & $\begin{array}{c}\text { Nhỏ } \\
\text { nhất }\end{array}$ & $\begin{array}{c}\text { Lớn } \\
\text { nhất }\end{array}$ & $\begin{array}{c}\text { Trung } \\
\text { bình }\end{array}$ & $\begin{array}{c}\text { Độ lệch } \\
\text { chuẩn }\end{array}$ \\
\hline Tuần hoàn ngoài cơ thể (phút) & 70 & 210 & 136 & 39,8 \\
\hline Thời gian cặp động mạch chủ (phút) & 50 & 180 & 106 & 36,7 \\
\hline Thời gian phẫu thuật (phút) & 150 & 310 & 230 & 41,2 \\
\hline
\end{tabular}


Bảng 3.4: Đặc điểm tổn thuơng và kĩ thuật phẫu thuật $(N=59)$

\begin{tabular}{|c|c|c|}
\hline \multicolumn{2}{|l|}{ Tổn thương van tim } & Số bệnh nhân (n, \%) \\
\hline \multirow{3}{*}{ Van hai lá } & Dạng thấp & $40(67,8 \%)$ \\
\hline & Dạng thoái hóa & $5(8,5 \%)$ \\
\hline & Khác & $7(11,8 \%)$ \\
\hline \multirow{4}{*}{ Van động mạch chủ } & Dạng thấp & $9(15,3 \%)$ \\
\hline & Dạng thoái hóa & $5(8,5 \%)$ \\
\hline & Dạng hai lá van & $2(3,4 \%)$ \\
\hline & Khác & $1(1,7 \%)$ \\
\hline \multirow{8}{*}{$\begin{array}{l}\text { Phẫu thuật thay van } \\
\text { hai lá }\end{array}$} & Thay van hai lá đơn thuần & $42(71,2 \%)$ \\
\hline & Thay đồng thời van hai lá, van động mạch chủ & $10(17,0 \%)$ \\
\hline & Qua đường mở vách trần & $49(83,0 \%)$ \\
\hline & Qua đường mở nhĩ trái & $3(5,1 \%)$ \\
\hline & Lấy huyết khối nhĩ trái & $15(25,4 \%)$ \\
\hline & Khâu bít tiểu nhĩ trái & $23(38,9 \%)$ \\
\hline & Đặt vòng van ba lá nhân tạo & $18(30,0 \%)$ \\
\hline & Sửa van 3 lá De Vega & $3(5,1 \%)$ \\
\hline \multirow{2}{*}{$\begin{array}{l}\text { Phẫu thuật thay van } \\
\text { động mạch chủ }\end{array}$} & Thay van động mạch chủ đơn thuần & $7(11,8 \%)$ \\
\hline & Kèm thay động mạch chủ lên & $1(1,7 \%)$ \\
\hline \multirow{2}{*}{ Loại van tim } & Van cơ học & $41(69,5 \%)$ \\
\hline & Van sinh học & $18(30,5 \%)$ \\
\hline
\end{tabular}

\subsection{Kết quả sớm sau phẫu thuật}

Bảng 3.5: Diễn biến sau mổ $(N=59)$

\begin{tabular}{|l|c|c|c|}
\hline \multicolumn{1}{|c|}{ Đặc điểm } & \multicolumn{3}{|c|}{ Kết quả } \\
\hline \multirow{2}{*}{ Thuốc vận mạch } & 1 thuốc & 2 thuốc & 3 thuốc \\
\cline { 2 - 4 } & $53(89,8 \%)$ & $5(8,5 \%)$ & $1(1,7 \%)$ \\
\hline \multirow{2}{*}{ Thời gian thở máy } & $<6 \mathrm{~h}$ & $6-12 \mathrm{~h}$ & $>12 \mathrm{~h}$ \\
\cline { 2 - 4 } & $53(89,8 \%)$ & $5(8,5 \%)$ & $1(1,7 \%)$ \\
\hline Thời gian nằm tại phòng hồi sức (ngày) & \multicolumn{3}{|c|}{$5,7 \pm 3,52(4-32)$} \\
\hline Thời gian nằm viện (ngày) & \multicolumn{3}{|c|}{$14 \pm 4,4(10-32)$} \\
\hline
\end{tabular}


Bảng 3.6: Biến chứng sau mổ $(N=59)$

\begin{tabular}{|l|l|c|}
\hline \multicolumn{1}{|c|}{ Biến chứng } & \multicolumn{1}{c|}{ Xử trí } & Số bệnh nhân (n, \%) \\
\hline Chảy máu & Phẫu thuật cầm máu xương ức & $1(1,7)$ \\
\hline Nhiễm trùng vết mổ & Thay băng, khâu lại & $5(8,5)$ \\
\hline Viêm xương ức & Mổ làm sạch, tạo hình xương ức & $1(1,7)$ \\
\hline Viêm túi mật cấp & Phẫu thuật cắt túi mật & $1(1,7)$ \\
\hline Viêm phổi & Điều trị nội khoa & $1(1,7)$ \\
\hline \multicolumn{2}{|l|}{ Tử vong (do suy tim cấp, suy đa tạng) } & $1(1,7)$ \\
\hline
\end{tabular}

Bảng 3.7. So sánh chỉ số siêu âm tim truớc và sớm sau mổ $(N=59)$

\begin{tabular}{|l|c|c|c|c|}
\hline \multicolumn{1}{|c|}{ Chỉ số siêu âm } & Trước mổ & Sau mổ & N & P \\
\hline Đường kính nhĩ trái (mm) & $48,2 \pm 10,26$ & $42,4 \pm 9,27$ & 59 & $<0,05$ \\
\hline Đường kính Dd (mm) & $51,5 \pm 7,63$ & $50,2 \pm 6,94$ & 59 & $<0,05$ \\
\hline Đường kính Ds (mm) & $34,3 \pm 6,42$ & $33,4 \pm 7,21$ & 59 & $<0,05$ \\
\hline Đường kính thất phải (mm) & $21,1 \pm 2,97$ & $20,5 \pm 2,33$ & 59 & $<0,05$ \\
\hline ALĐMP tâm thu (mmHg) & $47,1 \pm 12,28$ & $35,0 \pm 7,06$ & 59 & $<0,05$ \\
\hline Phân suất tống máu EF (\%) & $62,9 \pm 6,69$ & $64,3 \pm 7,84$ & 59 & $<0,05$ \\
\hline
\end{tabular}

\section{BÀN LUẬN}

\section{1. Đặc điểm trước phẫu thuật}

Tuổi trung bình trong nghiên cứu của chúng tôi là $53 \pm 11,7$ tuổi với tỉ lệ bệnh nhân ở độ tuổi lao động (dưới 60 tuổi) chiếm 72,9\%. Độ tuổi này thấp hơn nghiên cứu của các tác giả ở châu Âu do mô hình bệnh van tim ở Việt Nam chủ yếu là bệnh tim do thấp [1].

Trong nghiên cứu của chúng tôi, nguyên nhân bệnh sinh do thấp vẫn chiếm phần lớn (88\%), tương đương với các nghiên cứu bệnh van tim trước đây ở Việt Nam của Đặng Hanh Sơn, Mạc Thế Trường, Hoàng Trọng Hải [2-4]. Tại các nước phát triển thì bệnh van tim chủ yếu là bệnh van do thoái hóa và thiếu máu cơ tim; tỉ lệ bệnh van tim do thấp theo Caus là $54,2 \%$, còn lại $44,8 \%$ là do thoái hóa.

\section{Triệu chứng suy tim}

Trong nghiên cứu của chúng tôi, tất cả người bệnh đều có triệu chứng suy tim với tỷ lệ NYHA II chiếm 69,5\%, NYHA III chiếm 30,5\%. Kết quả này thấp hơn các nghiên cứu trước đó của Đặng Hanh Sơn, Hoàng Trọng Hải, Mạc Thế Trường [2-4] là do chúng tôi bắt đầu triển khai mổ tim hở nên lựa chọn kỹ, chủ yếu là các bệnh nhân nhẹ và trung bình để thực hiện phẫu thuật.

\section{Siêu âm tim}

Hiện nay, siêu âm tim qua thành ngực là thăm dò cận lâm sàng có giá trị nhất với các bệnh lý tim mạch nói chung và cũng như bệnh lý van tim. Tại Bệnh viện tỉnh Quảng Ninh, mỗi bệnh nhân trước mổ yêu cầu phải có 2 bản siêu âm tim do 2 bác sĩ khác nhau thực hiện. Ngoài ra chúng tôi có thể siêu âm qua thực quản, thông tim, chụp 
mạch vành để đánh giá chính xác hơn tổn thương nếu có sự chênh giữa các kết quả trước đó.

Kết quả chỉ số siêu âm tim trước mổ cho thấy có bệnh nhân đến viện ở giai đoạn muộn của bệnh, kích thước các buồng tim tăng: nhĩ trái giãn, lớn nhất đo được là $81 \mathrm{~mm}$, trung bình 48,2 mm; áp lực động mạch phổi tâm thu tăng cao, cao nhất là $82 \mathrm{mmHg}$, trung bình là $47,1 \mathrm{mmHg}$. Nhưng phần lớn bệnh nhân có phân suất tống máu EF còn tốt (trung bình $62 \%$ ), chứng tỏ chức năng thất trái còn khá tốt. Các kết quả này cũng tương đương với các nghiên cứu của các tác giả trong nước về tình trạng bệnh tim của các bệnh nhân đến viện mà có chỉ định phẫu thuật $[2,5]$.

Kết quả siêu âm tim cũng phản ánh nhóm bệnh thấp tim là chủ yếu với tổn thương dày dính, vôi lá van chiếm tỉ lệ cao nhất. Bệnh lý các lá van buồng tim trái hay kèm theo tổn thương van ba lá mà chủ yếu là hở van cơ năng do giãn buồng tim phải. Trong nghiên cứu của chúng tôi, tất cả các bệnh nhâh có hở van ba lá ở các mức độ khác nhau trong đó có $37,3 \%$ hở nặng cần phải sửa, kết quả này cũng phù hợp với các nghiên cứu của Nguyễn Hữu Ước 92,3\%; Đặng Hanh Sơn 99\%; Mạc Thế Trường 95,8\% [2, 4, 6].

\section{2. Đặc điểm phẫu thuật}

\section{Lụa chọn van nhân tạo}

Có 41 bệnh nhân (69,5\%) được sử dụng van tim cơ học chiếm và 18 bệnh nhân $(30,5 \%)$ sử dụng van tim sinh học. Các yếu tố chính để lựa chọn các loại van là:

- Tuổi: Tuổi trung bình trong nghiên cứu là $53 \pm 11,7$ tuổi. Theo khuyến cáo của ESC/EACTS năm 2012 thì tuổi phù hợp cho thay van nhân tạo sinh học là $\geq 65$ tuổi cho van động mạch chủ và $\geq 70$ tuổi cho van hai lá; hay theo khuyến cáo của ACC/AHA năm 2006 kết hợp điều kiện Việt Nam là cho bệnh nhân từ 60 tuổi trở lên. Trong nghiên cứu của chúng tôi có 38/43 bệnh nhân < 60 tuổi sử dụng van cơ học $[7,8]$.

\section{- Khả năng tuân thủ chống đông sau mổ}

Trong nghiên cứu của chúng tôi có 2 bệnh nhân dưới 60 tuổi, ở vùng núi và hải đảo không có điều kiện theo dõi đông máu thường xuyên, bệnh nhân và gia đình tự lựa chọn dùng van sinh học sau khi được nghe bác sĩ tư vấn về ưu và nhược điểm của từng loại van, biết được nguy cơ phải mổ lại thay van trong tương lai. 56\% bệnh nhân của chúng tôi đến từ khu vực nông thôn, miền núi, có điều kiện tiếp cận chăm sóc $\mathrm{y}$ tế, kiểm tra đông máu thường xuyên khó khăn. Việc lựa chon van sinh học là phù hợp với các khuyến cáo của $\mathrm{ACC} / \mathrm{AHA}, \mathrm{ESC}$, hội tim mạch học Việt Nam [8].

Các bệnh nhân rung nhĩ sau mổ đều phải duy trì thuốc chống đông kéo dài, do vậy 3 bệnh nhân $>60$ tuổi có tiên lượng sống lâu dài chúng tôi sủ dụng van cơ học để tránh cho bệnh nhân phải mổ lại để thay van trong tương lai.

\section{Đuờng vào bộc lộ van hai lá}

Để tiếp cận van hai lá có nhiều đường mở vào nhĩ trái. Mỗi đường mở đều có những ưu nhược điểm riêng. Tùy theo kinh nghiệm của phẫu thuật viên và tình huống cụ thể mà chọn đường mổ thích hợp.

+ Đường mở vách liên nhĩ (có thể kèm theo mở trần nhĩ trái): 51 bệnh nhân chiếm $94,6 \%$ được sử dụng đường này khi vào thay van hai lá. Bệnh nhân được mở dọc mặt trước nhĩ phải song song với rãnh nhĩ thất, sau đó mở dọc 
lỗ bầu dục kéo dài lên trần nhĩ trái hoặc không để vào nhĩ trái, thường áp dụng đường mở này đối với những bn có tiền sử phẫu thuật van hai lá (tách van tim kín, sửa van hoặc thay van hai lá), các trường hợp nhĩ trái nhỏ. Uu điểm của đường mở này là tiếp cận gần nhất với van hai lá [8]. Đường mổ rộng rãi, dễ thao tác trên van hai lá cũng như trong buồng nhĩ trái để lấy huyết khối và khâu tiểu nhĩ trái, kết hợp sửa van 3 lá mà không cần mở thêm buồng tim, do vậy chúng tôi ưa thích sử dụng đường này. Nhược điểm của đường này là cắt nhánh mạch nuôi nút xoang do vậy có thể ảnh hưởng tới nhịp tim sau mổ.

+ Đưòng mở nhĩ trái: chỉ có 3 bn mổ nhĩ trái theo đường này, đều là những bệnh nhân mổ lần đầu, và có kích thước nhĩ trái lớn. Uu điểm của đường mổ này là đơn giản, ít nguy cơ chảy máu. Tuy nhiên phẫu trường nhỏ, hẹp, khó thao tác, chúng tôi mới triển khai mổ tim hở chưa có nhiều kinh nghiệm nên ít chọn đường mổ này.

\section{Kỹ thuật sửa van ba lá}

Trong nghiên cứu của chúng tôi, có 22 bệnh nhân chiếm 37,3\% được sửa van ba lá, 18 bệnh nhân chiếm 30,5\% đặt vòng van nhân tạo, 3 bệnh nhân sử theo De Vega, 1 Bn được khâu mép van, có 37 bệnh nhân chiếm 52,7\% không phải can thiệp trên van ba lá. Các kết quả này cũng phù hợp với nghiên cứu của các tác giả trong nước như Đặng Hanh Sơn, Nguyễn Bá Phong, Mạc Thế Trường [2, 4, 5].

Thương tổn HoBL ở mức độ nhẹ không cần phải can thiệp, HoBL ở mức độ vừa $\geq 2 / 4$ cần thu nhỏ vòng van, HoBL 4/4 nên đặt vòng van nhân tạo. Việc tạo hình van ba lá sẽ giúp giảm bớt tình trạng suy tim phải sau mổ. Theo Matsuyama thì cần sửa van ba lá thật tốt ở những bệnh nhân có loạn nhịp, rung nhĩ, có NT giãn lớn và $\mathrm{HoBL}$ trước mổ $\geq 2 / 4$, vì đây chính là các yếu tố gây nên tình trạng HoBL nhiều sau mổ. Có nhiều phương pháp sửa van ba lá, tuy nhiên tùy theo kinh nghiệm của phẫu thuật viên và tùy tình trạng thương tổn cụ thể mà lựa chọn phương pháp phù hợp.

\subsection{Kết quả sớm sau phẫu thuật}

Thuốc vận mạch và hồi sức: Trong nghiên cứu của chúng tôi $89,8 \%$ dùng 1 thuốc, $8,5 \%$ dùng 2 thuốc và $1,7 \%$ dùng tới 3 thuốc vận mạch, kết quả này thấp hơn so với các nghiên cứu của các tác giả trong nước về thay van tim như Đặng Hanh Sơn, Nguyễn Bá Phong, Mạc Thế Trường, Hoàng Trọng Hải [2-5]. Điều này có thể được lý giải do chúng tôi lựa chọn bệnh nhân có tổn thương nhẹ hơn, do vậy ít cần thuốc trợ tim sau mổ. Thời gian nằm tại khu hồi sức mổ tim trung bình là 6 ngày và nằm viện sau mổ trung bình là $14 \pm 4,4$ ngày, thời gian ngắn nhất là 10 ngày, dài nhất là 32 ngày. Kết quả cho thấy sự chênh lệch lớn về thời gian nằm viện giữa các bệnh nhân. Thường với các bệnh nhân sau mổ diễn biến thuận lợi, không có biến chứng thì sau 3 ngày rút hết dẫn lưu, 7 ngày rút điện cực, 10 ngày sẽ cắt chỉ và ra viện. Tuy nhiên một số bệnh nhân có biến chứng: viêm phổi, suy tim, nhiễm trùng vết mổ, nhiễm trùng xương ức... sẽ làm thời gian nằm viện kéo dài, đặc biệt có 1 bệnh nhân suy đa tạng phải lọc máu và can thiệp $\mathrm{ECMO}$ nằm viện tới 32 ngày.

Siêu âm doppler tim sau mổ: Siêu âm tim sau mổ được tiến hành khi bệnh nhân ổn định và trước khi ra viện và thường được tiến hành từ 5-7 ngày sau mổ. Kết quả kiểm tra siêu âm sớm sau mổ cho thấy đường kính NT, đường kính TT, áp lực ĐMP tâm thu giảm đáng kể so với trước mổ 
(với $\mathrm{p}<0,05$ ). Điều này cho thấy hiệu quả ngay sau mổ của việc thay các van tim đối với những biến đổi giải phẫu và sinh lý bệnh. Kết quả siêu âm sớm sau mổ cho thấy tình trạng hoạt động của van nhân tạo tốt, không có trường hợp có hở cạnh van phải mổ lại. Chênh áp qua van như vậy là phù hợp với khuyến cáo của $\mathrm{ACC} / \mathrm{AHA} 2008$ và ESC 2012 [7].

\section{Biến chứng sớm}

+ Tư vong sớm sau mổ: Tỷ lệ tử vong sớm sau mổ bao gồm những bệnh nhân tử vong tại bệnh viện và tử vong trong khoảng 30 ngày sau phẫu thuật. Những trường hợp tuy chưa tử vong nhưng tình trạng nặng, tiên lượng tử vong cao, gia đình xin về chúng tôi cũng coi là tử vong sớm sau mổ. Trong nghiên cứu của chúng tôi có 1 bệnh nhân tử vong sớm chiếm tỷ lệ 1,7\%. Bệnh nhân tử vong là $\mathrm{Bn}$ nữ 60 tuổi, thay van hai lá và van động mạch chủ cơ học, sửa van ba lá, các diễn biến trong mổ không có gì đặc biệt, bệnh nhân được chuyển ra hậu phẫu và đã rút được ống nội khí quản, sau truyền hồng cầu và tiểu cầu thì xuất hiện suy hô hấp tuần hoàn, tổn thương mờ toàn bộ 2 phổi trên Xquang. Bệnh tiếp tục diễn biến nặng, suy đa tạng, viêm phổi, được lọc máu và ECMO nhưng không kết quả, tử vong hậu phẫu ngày thứ 32. Nguyên nhân được kết luận theo dõi hội chứng tổn thương phổi cấp sau truyền máu (TRALI). Các thống kê cho thấy hội chứng TRALI có tỉ lệ tử vong thấp ở các truyền máu thông thường có đông máu được kiểm soát nhưng rất cao ở nhóm bệnh nhân được phẫu thuật đặc biệt là phẫu thuật tim. Đây cũng là bệnh nhân tử vong sau mổ tim hở đầu tiên và duy nhất tại Bệnh viện cho đến thời điểm hiện tại. Tử vong sau mổ tim hở ở các trung tâm mới mổ tim như chúng tôi là điều khó tránh khỏi, dù chúng tôi cố gắng lựa chọn các bệnh nhân vừa phải, luôn có sự hỗ trợ của các chuyên gia và giải thích kỹ cho gia đình và bệnh nhân về nguy cơ này. Tỷ lệ tử vong sớm của chúng tôi thấp hơn khá nhiều so với các nghiên cứu của tác giả trong và ngoài nước, điều này được giải thích là do bệnh nhân chúng tôi lựa chọn có độ tuổi trung bình thấp hơn, tổn thương nhẹ hơn, được sự phẫu thuật bởi các chuyên gia đầu nghành nhiều kinh ngiệm.

- Chảy máu: Một bệnh nhân chảy máu sau mổ được mổ lại cầm máu xương ức với dẫn lưu trong 24 giờ đầu ra nhiều $>1500 \mathrm{ml}$. Một số bệnh nhân có lượng máu chảy qua dẫn lưu tương đối nhiều (100-150ml/ giờ trong những giờ đầu) được xử trí bằng truyền máu và điều chỉnh đông máu trước. Sau đó dẫn lưu ra giảm dần, diễn biến huyết động ổn định thì không phải mổ lại. Chảy máu sau phẫu thuật tim hở là biến chứng có thể gặp do chảy máu xương ức, bệnh nhân phải dùng thuốc chống đông máu trong quá trình phẫu thuật, thời gian phẫu thuật kéo dài và việc chạy máy tuần hoàn ngoài cơ thể cũng làm giảm số lượng và chất lượng các yếu tố đông máu. Tỉ lệ chảy máu sau mổ của các tác giả trong nước Đặng Hanh Sơn là 3,9\%; Mạc Thế Trường là 1,2 \% [2, 4]. Có thể hạn chế biến chứng chảy máu bằng việc cầm máu cẩn thận trước khi đóng vết mổ.

- Nhiếm trùng: Có 8 bệnh nhân bị sốt do viêm phổi chiếm tỷ lệ $13,5 \%$ phải thay kháng sinh và lý liệu pháp hô hấp sau đó ổn định. 1 bệnh nhân bị viêm xương ức phải mổ lại tạo hình xương ức. 5 bệnh nhân bị nhiễm trùng vết mổ chiếm tỷ lệ $8,4 \%$, vết mổ nề đau, chảy dịch đục, được tách vết mổ, lấy dịch cấy vi khuẩn nhưng không mọc, sau đó thay băng và khâu lại vết mổ, 
dẫn lưu áp lực âm sau 5 ngày. Nguyên nhân của các nhiễm trùng trên do trong thời gian đầu chúng tôi chưa có nhiều kinh nghiệm trong chăm sóc hướng dẫn bệnh nhân sau mổ, kỹ thuật đóng vết mổ chưa tốt, vẫn còn các khoang giữa các lớp giải phẫu là nơi đọng lại dịch hoặc do đốt vết mổ nhiều bằng dao điện dẫn đến vết mổ khó liền. Nhưng đợt mổ sau tỉ lệ này giảm hẳn do kinh nghiệm chăm sóc và đặt dẫn lưu áp lực trước và sau xương ức với những bệnh nhân có mô mỡ trước xương ức dày, xương ức yếu.

\section{Kết luận}

Triển khai phẫu thuật mổ tim hở nói chung và phẫu thuật thay van tim nói riêng tại Bệnh viện đa khoa tỉnh Quảng Ninh đã được thực hiện an toàn và hiệu quả. Tuy nhiên, ở giai đoạn đầu của quá trình này cũng có những khó khăn nhất định như trang thiết bị, vật tư còn thiếu kèm theo qui trình đưa vào sử dụng kéo dài, uy tín chuyên môn về lĩnh vực phẫu thuật tim của Bệnh viện chưa nhiều, cần có sự hỗ trợ chuyên môn trực tiếp của các chuyên gia... Bệnh viện đã nỗ lực và chủ động trong việc huy động mọi nguồn lực cùng với các chương trình hỗ trợ của hệ thống y tế trong và ngoài nước với mục đích giúp người bệnh tim mạch dễ dàng được phẫu thuật và chăm sóc ở gần nhà cũng nâng cao chất lượng chuyên môn chung của Bệnh viện.

\section{TÀI LIỆU THAM KHẢO}

1. Remadi J-P, Baron O, Tribouilloy C, Roussel JC, Al Habasch O, Despins P, et al. Bivalvular mechanical Mitral-Aortic valve replacement in 254 patients: Long-Term resultsa 22-year follow-up. The Annals of Thoracic Surgery. 2003;76(2):487-92.
2. Đặng Hanh Sơn. Nghiên cứu đánh giá kết quả phẫu thuật van hai lá bằng van tim nhân tạo cơ học Sorin tại Bệnh viện tim Hà Nội: Đại học Y Hà Nội; 2010.

3. Hoàng Trọng Hải. Nhận xét kết quả phẫu thuật thay van hai lá và van động mạch chủ bằng van nhân tạo sinh học tại bệnh viện Hữu nghị Việt Đức: Đại học Y Hà Nội; 2018.

4. Mạc Thế Trường. Đánh giá kết quả thay van hai lá nhân tạo sinh học tại bệnh viện Hữu Nghị Việt Đức: Đại học Y Hà Nội; 2017.

5. Nguyễn Bá Phong. Đánh giá kết quả phẫu thuật thay van hai lá sinh học SJM Biocor tại Trung tâm tim mạch: Đại học Y Hà Nội; 205.

6. Nguyễn Hữu Ước. Nghiên cứu ứng dụng đường mở nhĩ trái dọc qua hai van nhĩ - vách liên nhĩ mở rộng lên trần nhĩ trái trong phẫu thuật van hai lá: Đại học Y Hà Nội; 2004.

7. Baumgartner H, De Backer J, BabuNarayan SV, Budts W, Chessa M, Diller G-P, et al. 2020 ESC Guidelines for the management of adult congenital heart disease: The Task Force for the management of adult congenital heart disease of the European Society of Cardiology (ESC). Endorsed by: Association for European Paediatric and Congenital Cardiology (AEPC), International Society for Adult Congenital Heart Disease (ISACHD). European Heart Journal. 2021;42(6):563-645.

8. Nishimura RA, Otto CM, Bonow RO, Carabello BA. 2014 AHA/ACC Guideline for the Management of Patients With Valvular Heart Disease. J Am Coll Cardiol. 2014;63(22):e57-e185. 